\title{
The Variability of Critical Mass Loss Rate at Auto-Extinction
}

\author{
Snorri Már Arnórsson, Rory M. Hadden and Angus Law (iD*, School of \\ Engineering, The University of Edinburgh, Edinburgh, UK \\ Snorri Már Arnórsson, Verkís Consulting Engineers, Reykjavik, Iceland
}

Received: 16 December 2019/Accepted: 15 May 2020

\begin{abstract}
The conditions under which auto-extinction of timber can occur are of particular importance for mass timber structures where elements of structural timber are exposed, or become exposed, during a fire. Using experiments on $95 \mathrm{~mm}$ cubes of timber, the sensitivity of auto-extinction to sample orientation, and an imposed flow across the surface of the sample was investigated. It was found that the variation in burning rate between the vertical and horizontal orientation was $8 \%$ but that, for samples in a vertical orientation, auto-extinction occurred at a higher value of mass loss. It was found that while the critical mass loss rate for extinction was relatively consistent in a given orientation (coefficient of variation, 16\%), the variability in the time to extinction, and thus the total mass of timber consumed, was significant (coefficient of variation, $40 \%$ ). Critical mass loss for extinction was linked to the square of the flow velocity at the surface of the sample.
\end{abstract}

Keywords: Timber, Auto-extinction, Mass loss, Orientation, Protection of wood

\section{Introduction}

Auto-extinction of burning timber is frequently cited as key to achieving adequate safety in high rise mass timber buildings where elements of the structure are exposed (or become exposed) during a fire [1-4]. Drysdale [5] noted that 'it is 'common experience' that a thick slab of wood will not burn unless supported by... heat transfer from another source'; early work on the burning and auto-extinction of timber was recently summarised by Bartlett [6]. Auto-extinction occurs when the energy balance on the timber results in insufficient production of pyrolyzate to sustain flaming combustion. In order to determine whether auto-extinction can occur in a given compartment, it is necessary to understand the influence of the thermal and air flow environment on this process. Previous authors have investigated the conditions for auto-extinction of timber and their findings have been captured as the critical heat flux for auto-extinction $\left(\dot{q}_{c r i t}^{\prime \prime}\right)$ and/or the critical mass loss rate for extinction $\left(\dot{m}_{c r i t}^{\prime \prime}\right)[2,3,7,8]$. The critical heat flux for auto-extinction of timber has been reported in the range $30 \mathrm{~kW} / \mathrm{m}^{2}$ to $45 \mathrm{~kW} / \mathrm{m}^{2}$, and the critical mass loss rate for auto-extinction has been reported in the range $3.5 \mathrm{~g} / \mathrm{m}^{2} /$

\footnotetext{
*Correspondence should be addressed to: Angus Law, E-mail: angus.law@ed.ac.uk
} 
$\mathrm{s}$ to $4.0 \mathrm{~g} / \mathrm{m}^{2} / \mathrm{s}$. The findings of different authors are summarized in Table 1 with notes about each of the experimental programs. The experimental procedures for this previous work show notable differences. Emberley used the mass loss cone in the vertical orientation and samples were not insulated around the perimeter. Bartlett used the Fire Propagation Apparatus in the horizonal orientation and provided insulation around the perimeter (and base). It is perhaps unsurprising that different experimental arrangements lead to differences in the reported values of $\dot{q}_{c r i t}^{\prime \prime}$ and $\dot{m}_{c r i t}^{\prime \prime}$. The literature on auto-extinction (and the experimental work presented in this paper) focuses on the cessation of flaming combustion. It should be noted that smouldering combustion may continue even after the end of flaming and, while the mass burning rates associated with smouldering are comparatively lower than for flaming, this may still represent a hazard that should be addressed in the design of mass timber buildings.

Expanding from Emberley [1], the pyrolysis rate per unit area of a sample of timber can be expressed as follows:

$$
\dot{m}_{p}^{\prime \prime}=\frac{1}{\Delta H_{p}}\left[\dot{q}_{i n c}^{\prime \prime}+\dot{q}_{f}^{\prime \prime}+\dot{q}_{c h}^{\prime \prime}-\dot{q}_{\text {loss }}^{\prime \prime}-\left(-\left.k \frac{d T}{d x}\right|_{x=x_{c h}}\right)-\frac{\partial\left(\delta q^{\prime \prime \prime}\right)}{\partial t}\right]
$$

where $\dot{m}_{p}^{\prime \prime}$ is defined as the pyrolysis (mass loss) rate, $\Delta H_{p}$ is the heat of pyrolysis, $\dot{q}_{i n c}^{\prime \prime}$ is the applied heat flux (independent of any heat feedback from the flame), $\dot{q}_{f}^{\prime \prime}$ is the heat feedback from the flame; $\dot{q}_{c h}^{\prime \prime}$ is the energy generated due to reaction of the char, $\dot{q}_{\text {loss }}^{\prime \prime}$ is the heat losses from the surface, $k$ is the thermal conductivity of the timber, $\left.\frac{d T}{d x}\right|_{x=x_{c h}}$ is the thermal gradient of the heat losses into the virgin timber, $\delta$ is the thickness of the char layer and $\left(\delta q^{\prime \prime \prime}\right)$ is the energy stored per unit area of the char layer.

The significant differences in $\dot{q}_{c r i t}^{\prime \prime}$ observed in the literature suggests that there is variation in the terms of the energy equation between testing programmes. For example, differences may arise in experiments undertaken using the Cone Calorimeter compared to the Fire Propagation Apparatus, due to changes in the

\section{Table 1 \\ Results of Critical Mass Loss Rate at Extinction and Critical Heat Flux for Auto-extinction from Literature}

\begin{tabular}{lccl}
\hline Author & $\dot{m}_{\text {crit }}^{\prime \prime}\left(\mathrm{g} / \mathrm{s} / \mathrm{m}^{2}\right)$ & $\dot{q}_{\text {crit }}^{\prime \prime}\left(\mathrm{kW} / \mathrm{m}^{2}\right)$ & \multicolumn{1}{c}{ Notes } \\
\hline Emberley et al. [8] & $3.93 \pm 0.45$ & $43.6 \pm 4.7$ & $\begin{array}{l}\text { European spruce; mass loss cone; vertical } \\
\text { orientation; surface dimensions of } 120 \times 120 \mathrm{~mm}\end{array}$ \\
Emberley et al. [8] & $3.65 \pm 0.2$ & $44.6 \pm 0.9$ & $\begin{array}{l}\text { Radiata pine; mass loss cone; vertical } \\
\text { orientation; surface dimensions of } 120 \times 120 \mathrm{~mm}\end{array}$ \\
Bartlett et al. [2] & $3.48 \pm 0.31$ & 30 & $\begin{array}{l}\text { Spruce; fire propagation apparatus; horizontal } \\
\text { orientation; surface dimensions of } 85 \times 85 \mathrm{~mm}\end{array}$ \\
\hline
\end{tabular}



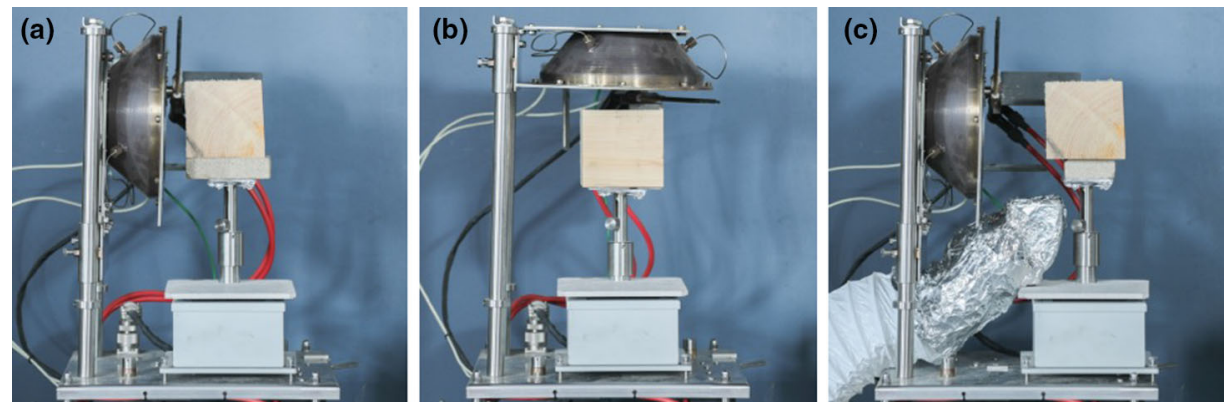

\section{Figure 1. a) Vertical orientation; (b) horizontal orientation; (c) vertical orientation with fan.}

convective heat transfer at the edge of the sample, absorptivity of the samples at different wavelengths; or sample size.

Conversely, although the literature shows some variation in $\dot{m}_{c r i t}^{\prime \prime}$, this variation is small $(\sim 13 \%)$ compared to the observed variation in $\dot{q}_{c r i t}^{\prime \prime}(\sim 50 \%)$. The relative insensitivity of $\dot{m}_{c r i t}^{\prime \prime}$ between the experimental programmes suggest that this term may provide a more reliable predictor of auto-extinction than a critical heat flux.

To develop understanding of the robustness of the critical mass loss rate criterion it is necessary to establish the: (1) variability in $\dot{m}_{c r i t}^{\prime \prime}$ for a given set of conditions; (2) difference in $\dot{m}_{c r i t}^{\prime \prime}$ between different applied heat fluxes; (3) difference in $\dot{m}_{\text {crit }}^{\prime \prime}$ for samples in different orientations; and (4) differences in the burning and extinction behaviour for samples subjected to an imposed flow across the surface.

\section{Experimental Methodology}

The experimental programme was undertaken using the mass loss calorimeter. Samples were of solid redwood timber with dimensions $95 \times 95 \times 95 \mathrm{~mm}$, a density of $488 \mathrm{~kg} / \mathrm{m}^{3} \pm 35 \mathrm{~kg} / \mathrm{m}^{3}$, with a conditioned moisture content of $12.5 \%$ (as measured on a dry basis). Samples were selected such that there were minimal imperfections or knots on the exposed face; grain orientation was perpendicular to the direction of heating (i.e. heating across the grain). The incident heat flux on the sample surface ( $25 \mathrm{~mm}$ away from the cone heater) was calibrated using a Schmidt-Boelter heat flux gauge and a pilot spark was used. The sample mass was recorded with a frequency of $1 \mathrm{~Hz}$; the duration of flaming was recorded.

To establish a baseline variation that should be expected in the parameters of interest, twelve experiments were conducted under an incident heat flux of $25 \mathrm{~kW} /$ $\mathrm{m}^{2}$ in the vertical orientation (Fig. 1a). To establish the variability of the mass loss rate and time to extinction under different heat fluxes and orientations, samples were tested in vertical and horizontal orientation (Fig. 1b) under 15, 25 and $35 \mathrm{~kW} / \mathrm{m}^{2}$. These values of heat flux were chosen to maximize the influence of $\dot{q}_{f}^{\prime \prime}$ which is expected to be proportionately more significant at low heat fluxes-a 
minimum of four repetitions were tested for each condition. The vertical orientation was analogous to a 'wall' configuration, while the horizontal orientation was analogous to a 'floor' configuration - with the cone heater located above the sample.

In the case of the forced flow, a simple arrangement (Fig. 1c) was used to impose the flow over the surface of the sample. The sample was positioned $75 \mathrm{~mm}$ away from the cone heater to allow the airflow to be delivered. The impact of this on the burning rate for extinction was characterized.

Four air velocities were imposed across the exposed face of the samples in the upwards vertical direction (i.e. the same direction as the buoyancy induced flow). The velocities were established prior to the experiments, in the absence of heating, using a hot wire anemometer. To establish the characteristic velocity across the surface, measurements were made in front of the sample and at the exit of the duct. The measured flow provides an indication of the free flow velocity in front of the sample. Four characteristic velocities were used as follows: $0.7 \mathrm{~m} / \mathrm{s}, 1.2 \mathrm{~m} / \mathrm{s}$, $1.7 \mathrm{~m} / \mathrm{s}, 2.3 \mathrm{~m} / \mathrm{s}$. It should be noted that the applicability of these values to full scale compartment fire tests has not been established.

Mass loss data were processed with 50-point moving averaging prior to presentation and analysis, and the start time (i.e. $t=0$ ) corresponded to the time of ignition. Heating was maintained for the entire duration of the each experiment.

This experimental setup allowed an investigation into the key parameters of interests. However, it should be noted that the scale of the samples is limited. Therefore, while it is possible to make direct comparisons between different variables for this scale, it does not necessarily follow that the conclusions would hold for samples or a larger scale.

\section{Results and Analysis}

Each experiment displayed relatively similar behaviour upon exposure to the incident heat flux. Immediately after ignition, flame lengths were relatively long, and over the duration of the experiment these gradually reduced in length; towards the end of the experiment flaming was localised around either cracks that had formed in the char, or around the edge of the samples. When the final flamelet was no longer visible, this was recorded as extinction. The results of the experiments are presented in three phases as follows: the baseline study of twelve samples; the heat flux/orientation study; and the forced flow study.

\subsection{Observations of Flame Extinction}

Observations during the experimental study indicate that flaming occurs in a localized area(s) on the sample surface for a significant time, and the time at which extinction would occur was influenced significantly by stochastic variables (e.g. crack formation, edge burning). Figure 2 shows two examples of such behaviour; it is notable that the crack locations form stochastically, however, in the experimental setup, the final flamelet location was noted to regularly (though not 

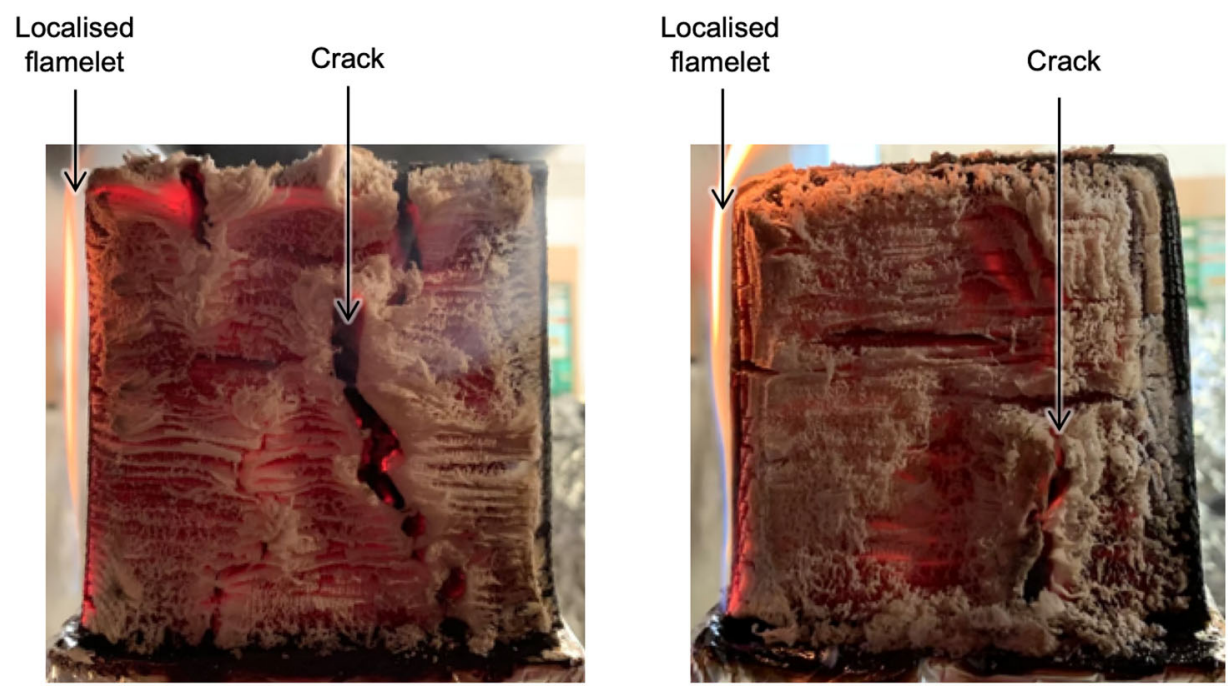

\section{Figure 2. Stochastic nature of sample surface and the final burning location.}

universally) be on the far left of the sample. The reason for this localisation is uncertain.

\subsection{Baseline Study}

The results for the baseline study are plotted in Fig. 3a. This plot shows the average mass loss rate and the mean critical mass loss rate for twelve samples exposed to $25 \mathrm{~kW} / \mathrm{m}^{2}$ in the vertical orientation up to the point of extinction. The shaded region indicates the maximum and minimum mass loss rate recorded for all experiments. The time to extinction for individual samples are also plotted.

It was found that the mean critical mass loss rate was $3.18 \pm 0.52 \mathrm{~g} / \mathrm{m}^{2} / \mathrm{s}$, and that the mean time to extinction was $2967 \pm 1192 \mathrm{~s}$. However, it is the variation between the individual experiments that is of particular interest. The coefficient of variation $(\mathrm{CV})$ was calculated for the mass loss rate, the time to extinction, and the critical mass loss rate.

The coefficient of variation is the ratio of the standard deviation to the mean and can be used to compare the relative variation between different datasets. $\mathrm{CV}$ for the mass loss rate is shown as a function of time in Fig. 3b. The mean CV for the mass loss rate was $14 \%$; the $\mathrm{CV}$ for critical mass loss rate was $16 \%$; and the $\mathrm{CV}$ for time to extinction was $40 \%$.

Unsurprisingly, the samples with longer times to flameout experienced a greater overall total mass loss. Figure 4 shows the normalized total mass loss from a sample depending on the time to extinction. The average mass loss rate of the samples until extinction, as derived from the gradient of the best fit line gives a value of $3.5 \mathrm{~g} / \mathrm{s} / \mathrm{m}^{2}\left(\mathrm{R}^{2}=0.96\right)$. 

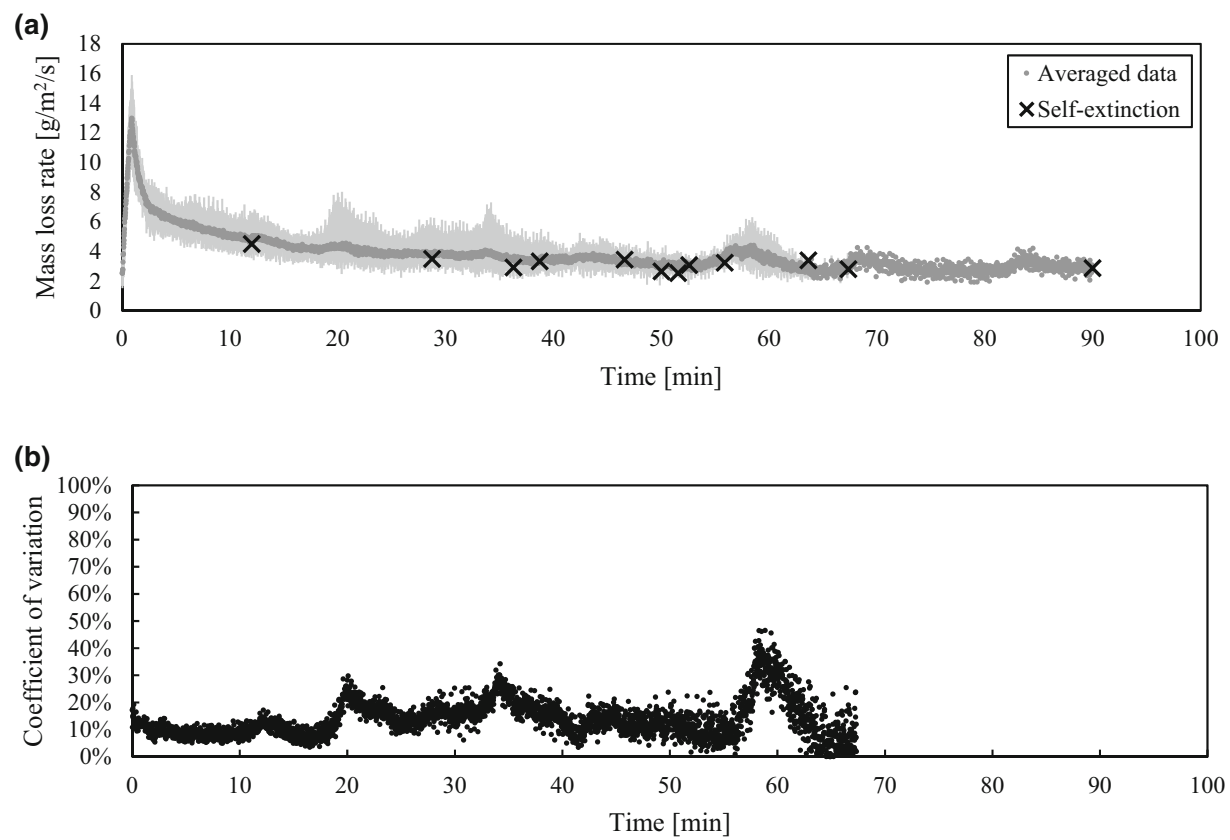

\section{Figure 3. (a) Average (mean) mass loss rate at every time for all data with overlaid critical mass loss rate for samples in vertical orientation; (b) coefficient of variation between mass loss rate data as a function of time (note that the CV after 67 min is zero because only one sample continued to burn after this time).}

The study of the baseline case allows a quantitative statement to be made about the variation of the parameters of interest. The primary finding of this study is that, $\dot{m}_{p}^{\prime \prime}$ and $\dot{m}_{c r i t}^{\prime \prime}$ are relatively consistent when compared against the time taken for the sample to extinguish. Thus, even though $\dot{m}_{c r i t}^{\prime \prime}$ can be relatively accurately defined; the time at which this occurs has significantly more variation. This results in a significant variation in the total mass lost from the sample (between $12 \%$ and $40 \%$ of the original mass).

An additional, and notable finding for the baseline study is that $\dot{m}_{c r i t}^{\prime \prime}$ was lower than the values obtained by Bartlett [2] and Emberley [8] - 3.2 g/s/m $\mathrm{m}^{2}$ compared against $3.5 \mathrm{~g} / \mathrm{s} / \mathrm{m}^{2}$ to $4.0 \mathrm{~g} / \mathrm{s} / \mathrm{m}^{2}$.

\subsection{The Effect of Orientation and Heat Flux}

The relation between $\dot{m}_{\text {crit }}^{\prime \prime}$ and applied heat flux can be further explored by analyzing the orientation and heat flux study. Typical mass loss rate data showing the effect of variation of heat flux and variation of orientation are shown in Fig. 5a, $\mathrm{b}$, respectively. This clearly shows that there are differences in the mass loss rate between the different heat fluxes, but that the difference appears to be smaller between horizontal and vertical orientations. 


\section{Table 2}

Overall Averages for Horizontal and Vertical Orientation at Different Heat Fluxes with Standard Deviation in Parentheses

\begin{tabular}{lccccc}
\hline & \multicolumn{2}{c}{ Horizontal } & & \multicolumn{2}{c}{ Vertical } \\
\cline { 2 - 3 } Heat flux $\left(\mathrm{kW} / \mathrm{m}^{2}\right)$ & $\dot{m}_{\text {crit }}^{\prime \prime}\left(\mathrm{g} / \mathrm{s} / \mathrm{m}^{2}\right)$ & $t_{\text {ext }}(\mathrm{s})$ & & $\dot{m}_{\text {crit }}^{\prime \prime}\left(\mathrm{g} / \mathrm{s} / \mathrm{m}^{2}\right)$ & $t_{\text {ext }}(\mathrm{s})$ \\
\hline 15 & $2.14(0.39)$ & $1987(793)$ & & $2.91(0.71)$ & $1436(448)$ \\
25 & $2.69(0.23)$ & $3220(398)$ & & $3.18(0.52)$ & $2967(1141)$ \\
35 & $2.45(0.56)$ & $4687(2616)$ & & $3.49(0.27)$ & $2079(663)$ \\
\hline
\end{tabular}

Data are the average of four experiments

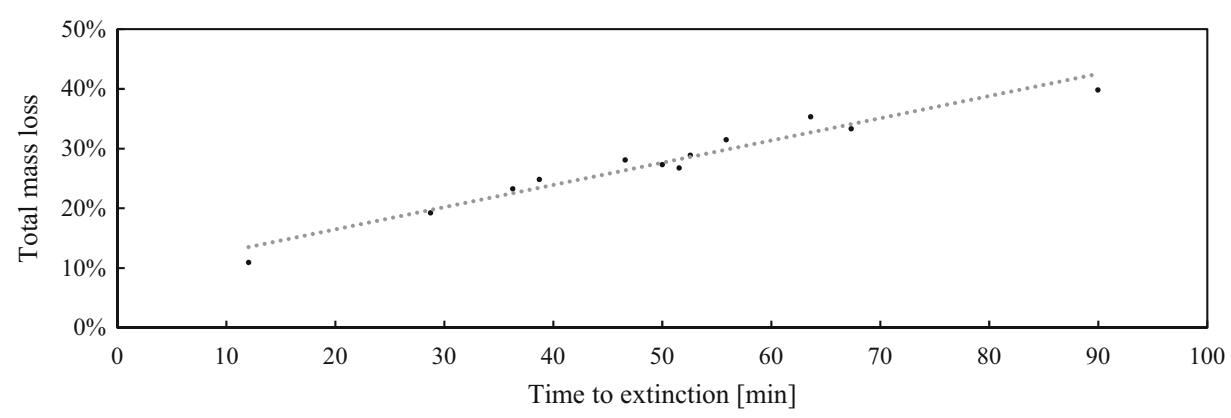

\section{Figure 4. Total mass lost from the samples under $25 \mathrm{~kW} / \mathrm{m}^{2}$ in the vertical orientation expressed as a percentage of the initial mass.}

The coefficient of variation between samples at the same heat flux and different orientations was calculated together with the coefficient of variation between samples at different heat fluxes, but the same orientation. In total 24 samples were tested at heat fluxes of 15,25 and $35 \mathrm{~kW} / \mathrm{m}^{2}$ in the vertical and horizontal orientations. It was found that the mean coefficient of variation between samples subject to different heat fluxes but at the same orientation was $26 \%$; the mean coefficient of variation for samples for the same heat flux but at different orientations was $8 \%$ (Fig. 3c).

The overall averages and standard deviations for mass loss rate at extinction and time of extinction are shown in Table 2. The longest time to extinction that was recorded occurred for a sample in the horizontal orientation exposed to a heat flux of $35 \mathrm{~kW} / \mathrm{m}^{2}$; for this sample the value of $\dot{m}_{\text {crit }}^{\prime \prime}=1.7 \mathrm{~g} / \mathrm{m}^{2} / \mathrm{s}$ and $t_{\text {crit }}=$ 8610 s.

Figure 6a shows the average and standard deviation of $\dot{m}_{c r i t}^{\prime \prime}$ for the different heat fluxes at different orientations. It is clear that $\dot{m}_{c r i t}^{\prime \prime}$ is consistently higher for the vertical orientation compared to the horizontal orientation. Figure $6 \mathrm{~b}$ shows similar data for $t_{\text {crit }}$; which indicates that the time to extinction was, on average, longer for the horizontal orientation compared to the vertical orientation. In the vertical orientation, the value of $\dot{m}_{c r i t}^{\prime \prime}$ increases with increased incident heat flux up 


\section{Table 3}

$\dot{m}_{c r i t}^{\prime \prime}$ as a Function of Velocity with Standard Deviation in Parentheses

\begin{tabular}{lr}
\hline Velocity $(\mathrm{m} / \mathrm{s})$ & $\dot{m}_{\text {crit }}^{\prime \prime}\left(\mathrm{g} / \mathrm{m}^{2} / \mathrm{s}\right)$ \\
\hline 0 & $3.14(0.15)$ \\
0.7 & $3.86(0.30)$ \\
1.2 & $4.21(0.10)$ \\
1.7 & $7.39(0.17)$ \\
2.3 & $8.98(0.67)$ \\
\hline
\end{tabular}

(a)

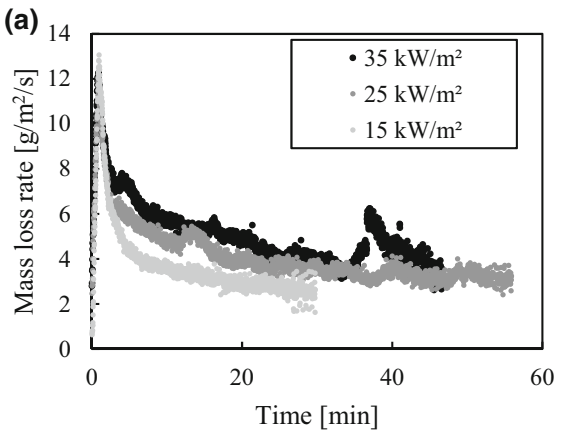

(b)

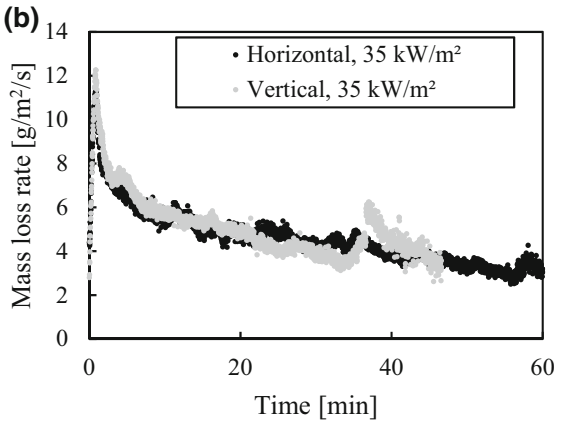

(c)

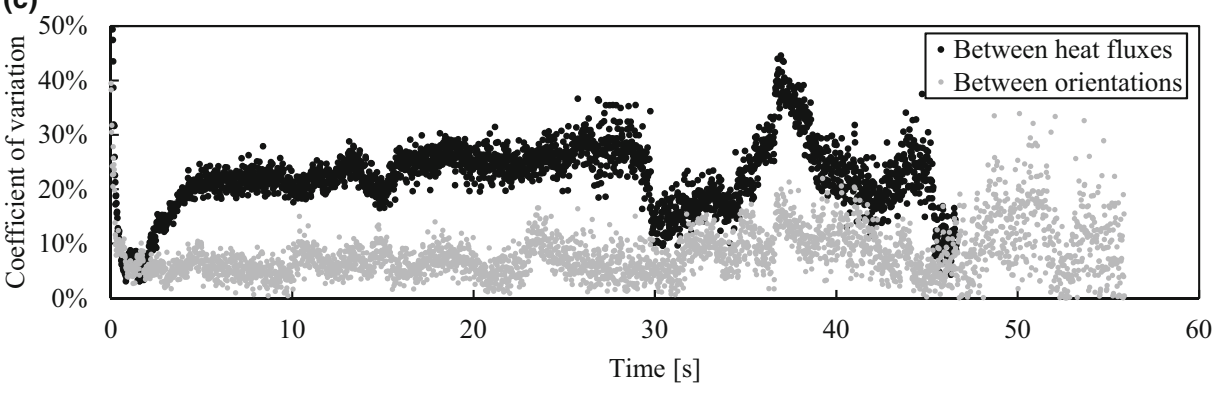

Figure 5. (a) Mass loss rate under different heat fluxes in the horizontal orientation; (b) mass loss rate under the same heat flux in different orientations; (c) coefficient of variation between heat variables.

to a value of around $3.5 \mathrm{~g} / \mathrm{s} / \mathrm{m}^{2}$ (in agreement with the literature under similar conditions). It should also be noted that the horizontal condition represents a "floor" configuration; it does not necessarily follow that the results for a horizontal "ceiling" would show the same behaviour. 

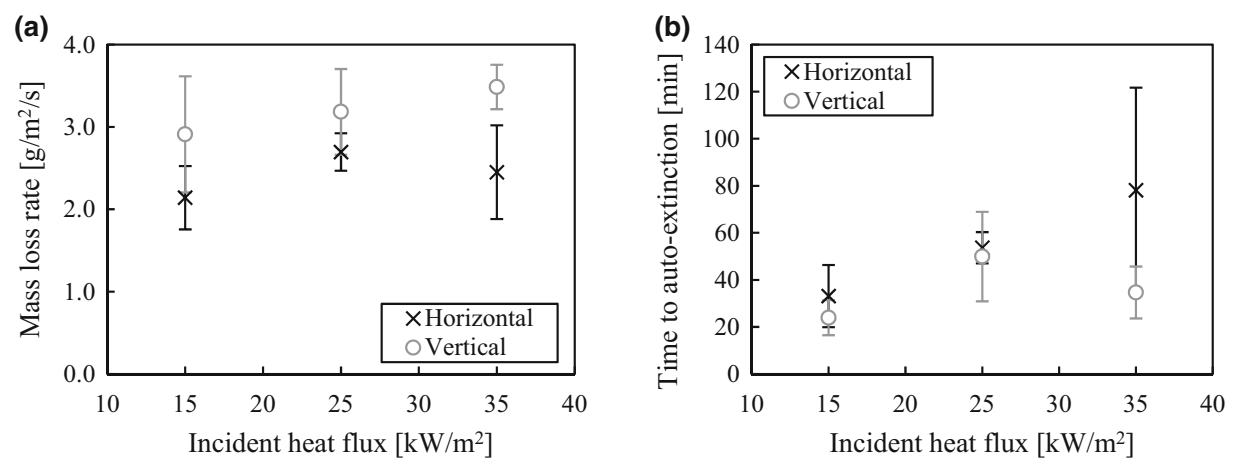

\section{Figure 6. (a) Change in $\dot{m}_{\text {crit }}^{\prime \prime}$ as a function of heat flux for the two dif- ferent orientations; (b) change in tarit as a function of heat flux for the two dierent orientations.}

\subsection{Forced Flow}

The introduction of a forced flow required the separation of the cone heater and the sample surface to be increased from $25 \mathrm{~mm}$ to $75 \mathrm{~mm}$ (in order to avoid cooling the cone heater with the forced flow). The baseline 'no flow' experiments were repeated in this configuration and form the basis of the subsequent comparison. It was found that, the average $\dot{m}_{\text {crit }}^{\prime \prime}$ was very similar $\left(3.13 \mathrm{~g} / \mathrm{m}^{2} / \mathrm{s}\right.$ compared to the original value of $3.18 \mathrm{~g} / \mathrm{m}^{2} / \mathrm{s}$ ); however, average mass burning rate was notably higher (a $\mathrm{CV}$ of $\sim 10 \%$ for mass burning rate compared to a $\mathrm{CV}$ of $<1 \%$ for $\dot{m}_{c r i t}^{\prime \prime}$ ). This behaviour appears to support the conclusion drawn from analyzing the literature that small changes in experimental setup may have a significant impact on the terms of the energy balance (and thus $\dot{q}_{c r i t}^{\prime \prime}$ ), but have minimal impact on $\dot{m}_{\text {crit }}^{\prime \prime}$.

The results of the forced flow experiments showed that mass loss rate increased as the characteristic velocity was increased. It also showed that extinction occurred at a higher value mass loss rate for higher characteristic velocities. Averaged mass loss data is shown in Fig. 7, and the values for critical mass loss rate as a function of velocity are shown in Table 3 .

\section{Discussion}

The difference between the $\dot{m}_{c r i t}^{\prime \prime}$ values obtained and those obtained by Emberley [8] and Bartlett [2], raises a question with regard to the definition of extinction and the degree to which a global mass loss rate per unit area can be used to define local behaviours. For example, where the overall incident heat flux is low, but there are local flamelets - burning may be sustained locally, but the average mass loss rate of the sample may be low. Conversely, where the overall incident heat flux is high, and there are local flamelets prior to extinction-burning may be sustained locally, but the average mass loss rate for the whole sample might be expected to be higher. It is possible that this may explain the differences in the 


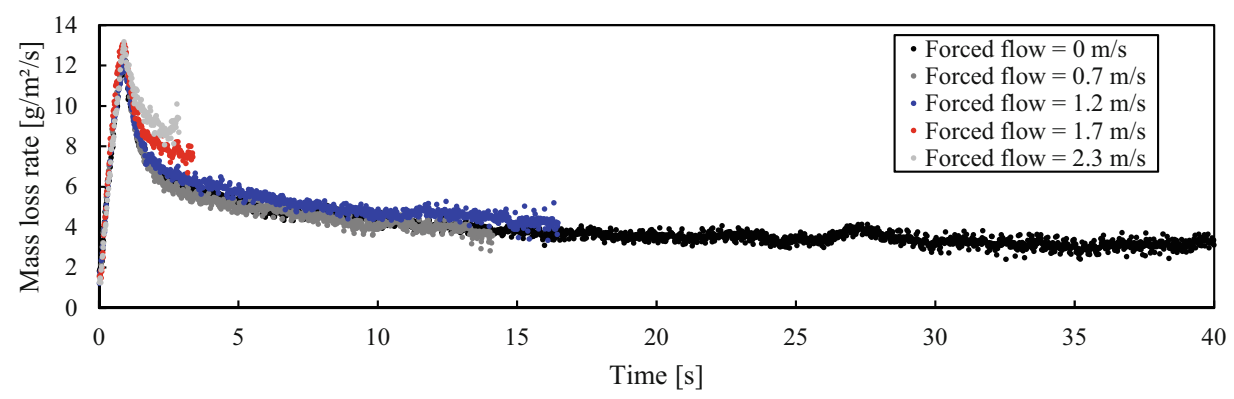

Figure 7. Mass burning rate under different forced flow conditions.

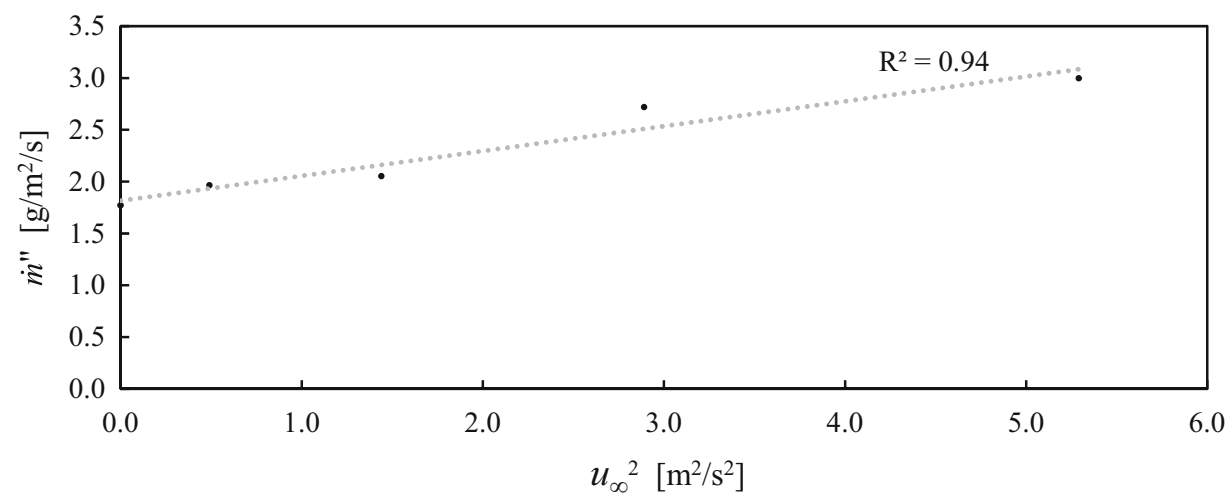

Figure 8. Proportionality between velocity of the forced flow and $\dot{\boldsymbol{m}}_{\text {crit }}^{\prime \prime}$

recorded $\dot{m}_{c r i t}^{\prime \prime}$ value obtained in this study and in the literature. Species and sample preparation may also contribute to differences.

This suggests that, overall, the global energy balance is not changed significantly between orientations. However, whether this means the contribution of the flame $\left(\dot{q}_{f}^{\prime \prime}\right)$ is unaffected by the sample orientation, or whether any changes to the flame are balanced by similar changes in char oxidation $\left(\dot{q}_{c h}^{\prime \prime}\right)$ and/or additional losses from the surfaces $\left(\dot{q}_{\text {loss }}^{\prime \prime}\right)$ cannot be defined based on these experiments. However, what these results demonstrate is that, for this configuration, orientation does not affect the overall mass loss rate of the sample.

\subsection{Forced Flow}

The results indicated that extinction is strongly related the velocity of the forced flow. Conditions for extinction are controlled by the Damkohler number $(D a)$, and literature $[9,10]$ indicates that the Damkohler number can be expressed as function of the inverse square of velocity. We have therefore attempted to analyse 
the data for critical mass loss rate in terms of the forced flow velocity. The Damkohler number is defined as the ratio between the characteristic residence time $\left(\tau_{r}\right)$ and the characteristic reaction time $\left(\tau_{c h}\right)$ :

$$
D a=\frac{\tau_{r}}{\tau_{c h}}
$$

Following Chen [11], Torero [9] the characteristic reaction time is:

$$
\tau_{c h}=\frac{1}{\rho_{\infty} A T_{f} e^{-E / R T_{f}}}
$$

where $A$ is the temperature dependent pre-exponential factor, $T_{f}$ is the flame temperature, $E$ is the activation energy $R$, is the universal gas constant, and $\rho_{\infty}$ is the density of the air. Residence time $\left(\tau_{r}\right)$ is given as:

$$
\tau_{r}=\frac{\alpha}{u_{\infty}^{2}}
$$

where $\alpha$ is the thermal diffusivity of the air, $u_{\infty}$ is the velocity of the air. This gives:

$$
D a=\frac{\tau_{r}}{\tau_{c h}}=\frac{\rho_{\infty} A T_{f} e^{-E / R T}}{\left(u_{\infty}^{2} / \alpha\right)}
$$

Chen [11] presented an alternate form of $D a$ whereby, the chemical reaction rate was expressed as a fixed value $\rho_{\infty} B$, where $B$ is the frequency factor (with units $\mathrm{m}^{3} / \mathrm{kg} / \mathrm{s}$ ). By adopting a similar assumption and one that is analogous to that made by Quintiere [10] the characteristic rate of reaction can be expressed as a function of the mass production rate of fuel per unit volume.

By making an assumption of proportionality between the mass production rate of fuel per unit volume and the mass production rate of fuel per unit area of the fuel surface, the Damkohler number can be expressed as a function of the pyrolysis rate as follows:

$$
D a=\frac{\tau_{r}}{\tau_{c h}} \propto \frac{\dot{m}_{p}^{\prime \prime} / \rho_{c}}{\left(u_{\infty}^{2} / \alpha\right)}
$$

where $\rho_{c}$ is the characteristic gas phase density. This formulation does not capture the dependency of the reaction rate on flame temperature; however, it does allow the conditions for $\dot{m}_{c r i t}^{\prime \prime}$ to be linked to a proportionality with $u_{\infty}^{2}$ as follows:

$$
\dot{m}_{c r i t}^{\prime \prime} \propto u_{\infty}^{2}
$$


Plotting this (Fig. 8) illustrates the correlation that would be expected. However, in plotting this it is notable that the flow velocity when the forced flow was set to zero would not, in fact, be zero due to the buoyancy effects of the hot gases formed in front of the sample. It follows from this that the extinction is dominated by the velocity of the forced flow, and it would appear that this proportionality holds even where local effects dominate the location of extinction.

\section{Conclusion}

Solid timber samples were exposed to a range of heat fluxes, characteristic velocities over the exposed face, and sample orientations. It was found that:

- Critical mass loss rate has a much lower coefficient of variation than time to auto-extinction (16\% compared to $40 \%$ ) - this indicates that while critical mass loss rate is a useful predictor of auto-extinction, stochastic effects and local behaviours can dominate the time at which auto-extinction occurs.

- Orientation had minimal impact on sample burning rate compared to the applied heat flux, but auto-extinction consistently occurred at a higher critical mass loss rate for samples in the vertical orientation compared to the horizontal orientation.

- Applying a forced flow resulted in a significantly greater mass loss rate and a higher critical mass loss rate at extinction. It was found that the mass loss rate at extinction was proportionate to the square of the flow velocity.

Predicting the extinction of timber is a necessary step to realising the design of compartments with exposed timber surfaces. While designers may be reliant on mass loss rate to predict the auto-extinction of timber, the variation in time to extinction may have a significant impact on the loadbearing capacity of any mass timber elements. It has been found that, as suggested by previous authors, mass loss rate is a reliable metric by which to anticipate auto-extinction of timber. However it is shown that, under constant external heating, the time to auto-extinction and, ultimately, the total mass lost from a sample can vary significantly.

The study on orientation demonstrates that, for the scale of sample studied, the orientation has relatively little impact on the burning rate-but that the critical mass loss rate for auto extinction is higher in the vertical compared to the horizontal orientation. In this study, the horizontal condition represents a "floor" configuration and the vertical condition a "wall" configuration; it does not necessarily follow that the results for a horizontal "ceiling" would show the same behaviour.

The origin of this difference can be attributed to the flow across the sample. The critical mass loss rate was shown to be proportionate to the square of the characteristic flow velocity at the timber surface. Again, in the context of design- 
ing compartments to achieve auto-extinction, these results suggest that the orientation and, indeed, length scale may play an important role.

The results demonstrate that extinction is controlled by local conditions close to the timber surface. In particular, application to real compartments will require detailed knowledge of the flow regime in the compartment as this has been shown to be significant in the determination of the critical mass loss rate. This raises the question of how this parameter can be reliably used in design.

The results and analysis both confirm previous findings in the literature and raise a series of issues regarding the application of such data by designers aiming to achieve auto-extinction. Of particular interest is developing a better understanding of how increased length scale may affect these results; identifying the role of orientations other than those tested here (e.g. exposed timber soffits) and evaluating appropriate criteria to capture the local processes which govern auto-extinction.

\section{Acknowledgements}

The authors would like to acknowledge EPSRC Grant Fire Spread from Mass Timber Buildings (EP/R012296/1), BRE Trust, and Grant support for the lead author from Mannvirkjastofnun (The Icelandic Construction Authority).

\section{Open Access}

This article is licensed under a Creative Commons Attribution 4.0 International License, which permits use, sharing, adaptation, distribution and reproduction in any medium or format, as long as you give appropriate credit to the original author(s) and the source, provide a link to the Creative Commons licence, and indicate if changes were made. The images or other third party material in this article are included in the article's Creative Commons licence, unless indicated otherwise in a credit line to the material. If material is not included in the article's Creative Commons licence and your intended use is not permitted by statutory regulation or exceeds the permitted use, you will need to obtain permission directly from the copyright holder. To view a copy of this licence, visit http://creat ivecommons.org/licenses/by/4.0/.

\section{References}

1. Emberley R, Putynska CG, Bolanos A et al (2017) Description of small and large-scale cross laminated timber fire tests. Fire Saf J . https://doi.org/10.1016/j.firesaf.2017.03.024 
2. Bartlett AI, Hadden RM, Hidalgo JP et al (2017) Auto-extinction of engineered timber: application to compartment fires with exposed timber surfaces. Fire Saf J. https://doi.or $\mathrm{g} / 10.1016 / \mathrm{j}$.firesaf.2017.03.050

3. Crielaard R, van de Kuilen J-W, Terwel K et al (2019) Self-extinguishment of crosslaminated timber. Fire Saf J 105:244-260. https://doi.org/10.1016/j.firesaf.2019.01.008

4. Bateman CJ, Bartlett AI, Rutkauskas L, Hadden RM (2018) Effects of fuel load and exposed CLT surface configuration in reduced-scale compartments. In: World conference on timber engineering, Seoul

5. Drysdale D (2011) An introduction to fire dynamics. Wiley, Chichester

6. Bartlett AI, Hadden RM, Bisby LA (2019) A review of factors affecting the burning behaviour of wood for application to tall timber construction. Fire Technol 55:1-49. https://doi.org/10.1007/s10694-018-0787-y

7. Emberley R, Inghelbrecht A, Yu Z, Torero JL (2016) Self-extinction of timber. Proc Combust Inst. http://dx.doi.org/10.1016/j.proci.2016.07.077

8. Emberley RL (2017) Fundamentals for the fire design of cross laminated timber buildings. The University of Queensland, St. Lucia

9. Torero JL, Vietoris T, Legros G, Joulain P (2002) Estimation of a total mass transfer number from the standoff distance of a spreading flame. Combust Sci Technol 174:187203. https://doi.org/10.1080/713712953

10. Quintiere JG, Rangwala AS (2004) A theory for flame extinction based on flame temperature. Fire Mater 28:387-402. https://doi.org/10.1002/fam.835

11. Chen C-H, Hou W-H (1991) Diffusion flame stabilization and extinction under naturally convective flows. Combust Flame 83:309-324. https://doi.org/10.1016/0010-2180(9 1) $90078-\mathrm{P}$

Publisher's Note Springer Nature remains neutral with regard to jurisdictional claims in published maps and institutional affiliations. 